DATA DE

RECEPCIÓN:

08/09/2020

DATA DE

ACEPTACIÓN:

$15 / 11 / 2020$

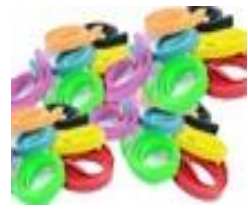

\section{LITERATURA INFANTOJUVENIL E QUESTÕES DE GÉNERO: CASOS QUE SÃO “CINCO CANTINHOS” NA RODA PRIVADA OU SOCIAL}

\author{
LITERATURA INFANTIL Y JUVENIL Y CUESTIONES DE GÉNERO: \\ CASOS QUE SON “CINCO CANTINHOS” EN LA RUEDA PRIVADA O SOCIAL
}

\author{
CHILDREN'S AND YOUNG ADULT LITERATURA AND GENDER ISSUES: \\ CASES THAT ARE “CINCO CANTINHOS” INTHE PRIVATE OR SOCIAL CIRCLE
}

\author{
Cláudia Sousa Pereira \\ CIDEHUS - Universidade de Évora \\ https: / / orcid.org/0000-0002-7298-3945 \\ cpereira@uevora.pt
}

Resumo: Neste texto partiremos de cinco obras dedicadas ou adaptadas à leitura por crianças. Quatro delas são textos e livros de géneros e suportes diferentes, publicados em Portugal entre 1965 e 2011, que retratam, questionam ou promovem comportamentos relacionados com estereótipos de género, em vários âmbitos, e em que o espaço íntimo da família e da casa é preponderante, embora não exclusivo, sobretudo nos mais recentes. Chegaremos a uma quinta obra, não publicada em Portugal, de autoria de um famoso youtuber britânico, que talvez nos ajude a ler melhor o futuro da representação, em literatura para os mais novos, das questões de género. Escolhemos este percurso para, a partir dos enredos ficcionais estudados, levantar e propor respostas, ou pelo menos linhas para a discussão, sobre as seguintes questões: 1) a consciência da diferença parte da pressão social ou da orientação individual? 2) o convívio intergeracional pode promover a continuidade ou, pelo contrário, incentivar a contestação aos preconceitos de género? 3) e essas, a continuidade ou a contestação, dependem, fundamentalmente, da cíclica generation gap ou antes de mudanças societais?

Palavras-chave: literatura infantojuvenil, livro e media, questões de género, mudanças societais.

Resumen: En este texto partiremos de cinco obras dedicadas o adaptadas a la lectura de los niños. Cuatro de ellos son textos y libros de diferentes géneros y soportes, publicados en Portugal entre 1965 y 2011, que retratan, cuestionan o promueven comportamientos relacionados con los estereotipos de género, en diversos ámbitos, y en los que el espacio íntimo de la familia y el hogar es preponderante, aunque no exclusivo, especialmente en los más recientes. Llegaremos a un quinto trabajo, no publicado en Portugal, de un famoso youtuber británico, que nos puede ayudar a leer mejor el futuro de la representación de género en la literatura para los más jóvenes.

Escogemos este camino para, entre las tramas ficticias estudiadas, plantear y proponer respuestas, o por lo menos líneas de discusión, sobre las siguientes preguntas: 1) la conciencia de la diferencia es parte de la presión social o de la orientación individual? 2) puede la interacción generacional promover la continuidad o, por el contrario, fomentar el desafío de los prejuicios de género? 3) y estas, la continuidad o la contestación, dependen, fundamentalmente, de la generation gap o antes de los cambios sociales?

Palabras clave: literatura infantil y juvenil, libro y media, cuestiones de género, cambios sociales.

\begin{abstract}
In this text we will start from five works dedicated or adapted to children's reading. Four of them are texts and books of different genres and media, published in Portugal between 1965 and 2011, which portray, question or promote behaviours related to gender stereotypes, in various areas, and in which the intimate space of the family and home is predominant, although not exclusive, especially in the more recent ones. We will come to a fifth work, not published in Portugal, by a famous British youtuber, which can help us better read the future of gender representation in literature for the youngest.

We chose this path to, among the fictitious plots studied, raise and propose answers, or at least lines of discussion, on the following questions: 1) is awareness of difference part of social pressure or individual orientation? 2) can generational interaction promote continuity or, conversely, foster the challenge of gender bias? 3) and these, the continuity or the answer, depend, fundamentally, on the generation gap or before the social changes? Keywords: children's and young adult literature, book and media, gender issues, social changes.
\end{abstract}

Sousa Pereira, Cláudia (2020).

"Literatura infantojuvenil e questões de género: casos que são "Cinco Cantinhos" na roda privada ou social". Elos. Revista de Literatura Infantil e Xuvenil, 7, "Artigos", 157 173. ISSN 2386 7620. DOI http://dx.doi.org/10.15304/elos.7.7091 


\section{Introdução}

Tendo passado de tema fraturante na sociedade a campo de estudos académicos com crescente produção na área das Ciências Sociais e Humanas, as questões que se levantam e tentam resolver-se em torno do género, desde a condição feminina à identidade, partem de dois movimentos que talvez consideremos contraditórios mas que, quase naturalmente, podem resultar em sinergia: o preconceito e a tolerância. É porque há preconceito que é urgente a tolerância.

Por outro lado, na sociedade ocidental, ou ocidentalizada, começou a ganhar uma escala considerável a diluição da fronteira entre o público e o privado, entre o que acontece na vida da intimidade ou na vida partilhada em comunidade. De certa forma, estas duas tendências de tensões em equilíbrio -preconceito/tolerância e público/privado- são novidades relativas nos meios urbanos, mas não tão surpreendentes nas comunidades rurais. E esta dinâmica que opõe urbanidade/ruralidade, num sentido de ajudar a resolver eventuais conflitos com alterações de comportamentos individuais em sociedade, pode encontrar semelhanças nas dinâmicas passado/presente, se considerarmos a evolução da sociedade, cruzando-se com infância/maioridade na evolução individual.

Do mundo-macro para o mundo-micro, de forma a regressar, compreendendo melhor, ao coletivo através do individual, são estes os sentidos que podem contribuir para que a ciência, seja ela qual for, procure nos padrões a equação que melhor se adequa ao desejo de progresso e, finalmente, à conquista de um cada vez maior bem-estar dos indivíduos e das sociedades. Tarefas árduas, sempre incompletas, em constante demanda.

Os dois autores que enquadram teoricamente os cinco “casos sociais" que estudámos para tratar os dois fenómenos em tensão - preconceito/tolerância e público/privado- em objetos culturais dirigidos a públicos infantojuvenis, não são autores propriamente muito recentes, mas representam uma atitude que, em nosso entender, cinco décadas depois, passou de mera suspeição profética para se confirmar como adequada e, com a vantagem da antecipação, útil. Projeções feitas por Marshall McLuhan (em 1962) e Elias Canetti (em 1960) que, no advento da modernidade resultante da evolução da técnica e da ciência, têm contribuído para confirmar comportamentos humanos e sociais, individuais e coletivos, e deles serem criados e implementados produtos, chamemos-lhe assim, que potenciem finais mais felizes ou, pelo menos, evitem a repetição de catástrofes comparáveis, diacronicamente, com as guerras, sobretudo mas não só as mundiais, que dizimaram e traumatizaram gerações. Tomaremos como referência as obras que considerámos representativas da importância dos dois teóricos, sem ignorar que noutras obras desenvolveram as suas ideias e tomaram novos casos que completaram e ajustaram as suas formas de pensar o mundo. De McLuhan relemos The Galaxy of 
Gutemberg (1962) e de Canetti Masse und Machte (Crowds and Power) (1960).

Para além de cotejarmos os dois autores, referindo-nos ao que neles encontrámos que viesse trazer-nos alguma luz no campo dos estudos literários contemporâneos aplicados à promoção da leitura literária, para depois chegarmos à temática deste texto, importa ainda fazermos uma breve contextualização relativamente ao campo de estudo da literatura infantojuvenil onde nos movemos. Faremos depois uma breve leitura interpretativa de cada um dos cinco livros, a partir das questões que quisemos levantar, experimentando os conceitos e as discussões que em torno deles podem revelar-se úteis no tratamento do tema "questões de género". Esta abordagem torna-se, na nossa perspetiva, também importante na promoção de uma leitura literária que ultrapasse o patamar da leitura para distração e contribua para uma concentração que a arte verbal proporciona ao seu recetor, tornandoo, para além de ávido, um melhor leitor.

Importa ainda, para fecharmos esta introdução, esclarecermos desde já a referência ao jogo tradicional dos Cinco Cantinhos do nosso título, e que, porque metafórica, não é gratuita. Descrevamos o jogo: começa-se por se desenhar cinco cantinhos no chão de um qualquer terreno livre, onde jogarão seis jogadores; o objetivo é trocar de lugares sem perder o lugar para aquele que está no meio. No desenrolar do jogo, cinco jogadores metem-se nos cinco cantinhos que foram desenhados no chão e fica um, tirado à sorte, a pedir lume ao meio; se dissermos que não, ele vai a outro pedir, se dissermos que sim, ele vai para o nosso cantinho e esse que disse que sim vai para o meio pedir lume. Enquanto vai pedir lume, os outros trocam de lugar entre si, mas o do meio tenta ver se consegue apanhar o lugar de algum que se distraia.

A puerilidade primordial do jogo exercita a destreza física, a perspicácia na antecipação dos movimentos do Outro, visando a usurpação do lugar por quem não o tem, bem como a procura, arriscada, de um melhor lugar por quem já conquistou, talvez até pela sorte, um lugar confortável, mas fastidioso. Uma procura nem que seja da novidade, cujos pequenos sucessos ao longo do percurso, sem final grandioso previsto, se resume à única recompensa da demanda dos pequenos heróis que vão girando, numa dinâmica que parece impor-se como único movimento válido (o jogador que nunca sai do seu lugar fica a dever ao implícito fairplay exigido). Já o lado "sério" do ludismo leva-nos a olhar para este jogo como exercício de relações de poder, de movimentações que alertam para a efemeridade e fragilidade do poder, proporcionando, ao mesmo tempo, a experiência de nos colocarmos na pele de quem não tem lugar. Seja porque ainda não teve ou porque já não tem ${ }^{1}$.

Também a ficção que se joga na Literatura, e na Arte em geral, permite relacionar o

\footnotetext{
${ }^{1}$ Deixaremos de parte, sem ignorar, o facto desfasado na atualidade do comportamento de "pedir lume", prova da idade do jogo.
} 
fingimento de situações com referentes na realidade. E é por isso que, também nos livros, sobretudo nos bons livros, os códigos (verbal e icónico, nos exemplos que daremos) podem ser usados para neles serem (re)criados pequenos mundos que, mais ou menos, o são à semelhança do real. E a leitura literária, se num primeiro momento se confunde com a leitura tout court e apenas nos parece entreter e distrair, aprofunda o tratamento de determinadas temáticas, onde as questões de género surgem aqui, explicita ou subliminarmente, de forma programática ou, se não, pelo menos sujeitas a leituras que as tomem assim.

Reúne-se neste texto um conjunto de reflexões que partem de livros infantojuvenis tomados como "cantinhos" ou lugares onde a leitura literária permite assumir-se como atividade com um potencial que enriquecerá não só os próprios livros, como os seus jovens leitores implícitos. Estas reflexões poderão constituir pistas de trabalho sobre questões de género, para um mediador que, no sistema plural da Literatura em geral, e no subsistema da LIJ em particular, tem sempre uma função importante, como adiante veremos.

\section{Os cinco livros}

De Mãos Dadas, Estrada Fora é uma antologia de Luísa Dacosta, inicialmente publicada em dois volumes (1970-73), com outros dois que ficaram inéditos, em que a escritora reúne excertos de textos de autores canónicos da língua portuguesa. Cada autor e cada excerto têm breves introduções de Luísa da Dacosta, em que realça normalmente a presença da criança, o retrato literário de determinadas situações de cariz social e até político, para além de chamadas de atenção para o uso da língua moldado pela arte do autor. Para além de ser uma antologia que contribui para o cânone escolar, até porque Luísa Dacosta foi toda a vida professora de Português, é notória, na escolha dos excertos e nas breves e poéticas introduções que lhes faz, uma intenção política que se disfarça de literatura, pelo contexto das circunstâncias históricas em que é editada a obra.

Ao lado da criança, que de destinatário da obra é também personagem principal de textos e do futuro da humanidade, a condição feminina também é assunto. Destacamos dois momentos em que esta condição é denunciada. A primeira, logo a abrir a obra, a propósito de Irene Lisboa, de quem Luísa Dacosta diz assim:

Triste foi a sua vida. Não conheceu mãe e teve madrasta, como a Gata Borralheira! Menininha, vivia muito só. Não, não se conformava. Quem podia ter conformação? E tão forte foi o seu querer que chegou para povoar seus mundos. Companheiros como os dela ninguém teve: a estrela azul, as figuras do tapete, a pata rainha, princesas serranas e príncipes cavadores, pois era rebelde e não queira saber de usos e costumes. Por suas mãos talhou leis. Quando cresceu, tornou-se uma grande, grande escritora. Lembrou-se, então, das velhas histórias que tinha inventado para encher a sua vida sozinhinha e triste. E 
passou-as ao papel, para servirem de companhia a outros meninos. Não foi uma ideia generosa? (Dacosta, 2002:11)

A condição feminina aproximada da condição de criança triste, evocada na figura da Gata Borralheira, símbolo da exploração envolto na mensagem do destino que pode ser contrariado, se bem que a muito poder de elementos maravilhosos.

Já para introduzir Almeida Faria, e o excerto do romance $A$ Paixão, o tom de esperança desaparece. Acaba-se o maravilhoso, a realidade denuncia-se:

Miúdas, invisíveis quase, rotina são sem aventura, emalhadas na malha dos dias e das horas, saturantes, assalariadas por baixo preço, comida e alojamento inferiores - assim as tarefas de mulher. Feitas hoje e amanhã, amanhã e depois, pisadas por todos, que todos sujam com indiferença e sem remorsos, apesar de saídas de mãos que não comem antes do trabalho, antes de lhes sair o suor do esforço a lavar, a esfregar, a varrer. Canga que antecipadamente pesa, como a desta criada alentejana, que, no clarear da antemanhã e antes de enregar o trabalho, de retomar os gestos de todos os dias, fardo de séculos, rememora, dando-se a um exercício mental de pessoa humana, as manhãs sempre iguais que a transformam num animal de trabalho sem horizontes nem compensações. (Dacosta, 2002: 119)

Curiosamente, e voltando ao princípio da antologia, a propósito dos contos tradicionais enquanto transmissores de sabedoria popular, as tarefas domésticas a cargo das mulheres voltam a ser assunto. Luísa Dacosta escolhe um conto em que intervêm duas mulheres, e sobre o qual diz o seguinte:

Venham ouvir uma história para guardar! É a d' OS DEZ ANÕEZINHOS DA TIA VERDE-ÁGUA, uma velhotinha que todos julgavam coberta pelos favores das fadas, de tal maneira era mulher entendedora e de bom conselho. Conselho de mão cheia, para servir toda a vida, pois é mais que certo que só nos ajuda quem nos ajuda a fazer sozinhos. (Dacosta, 2002: 26)

Ainda que a personagem da mulher desleixada ${ }^{2}$ possa ser vítima de violência doméstica que não se denuncia, pondo-se até ênfase nesse seu lado de desleixo, é a inteligência de outra mulher que Luísa Dacosta realça. Não há nem o louvor da rebeldia, que houve a propósito de Irene Lisboa, nem o tom de denúncia sobre a personagem da criada alentejana de Almeida Faria. Mas nos três casos há, claramente, lugar para a consciência da condição e um encontrar de soluções que permitam lidar com essa condição, tudo dentro das limitações que as circunstâncias das diversas realidades ditam e que conferem a verosimilhança reclamada mesmo na ficção.

O excerto de Uma Mão Cheia de Nada e Outra de Coisa Nenhuma, que põe uma Rosalina sozinha e sonhadora, obediente mas só dentro dos limites da sua ilimitada imaginação, termina assim:

Rosalina atrapalhada voltou para trás e por aquela praia fora correu tanto, tanto, tanto que ia morrendo. Chegou a

\footnotetext{
${ }^{2} \mathrm{O}$ conto trata de uma mulher a quem o marido maltrata por ser desleixada nas tarefas domésticas. A mulher vai pedir ajuda a uma mulher com fama de ter poderes sobrenaturais e que a aconselha a ir fazendo com as suas próprias mãos as suas tarefas de casa que ela enviará dez anõezinhos para a ajudar. Ora, a mulher faz todas as tarefas convencida de que é ajudada quendo, afinal, os dez anõezinhos são os dedos das suas duas mãos.
} 
casa de noite fechada. Já a mãe andava à procura dela pelas vizinhas, muito aflita: tinha mandado a sua pequena a um recadinho ali tão perto... (Dacosta, 2002: 14)

O conto popular tradicional, recolhido por Teófilo Braga, uma quase adivinha também para os pequenos ouvintes, desenlaça-se assim:

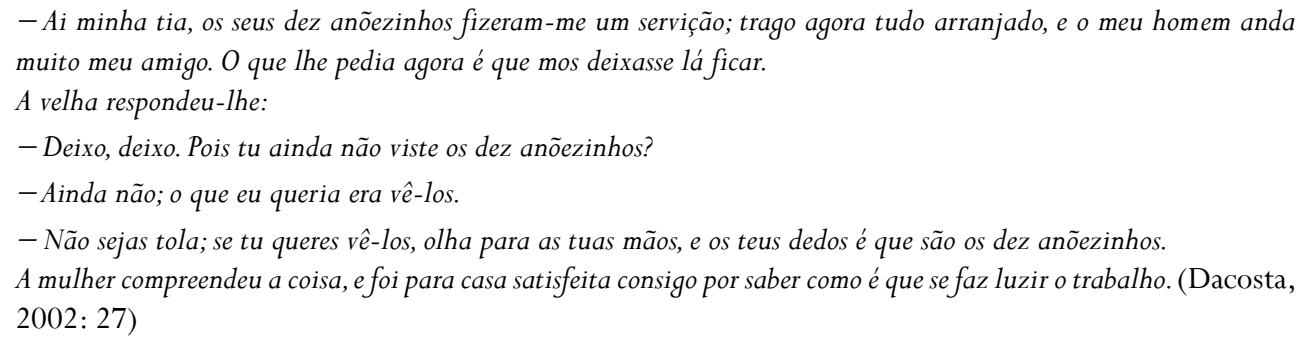

O longo e único parágrafo, que pede uma leitura de um fôlego só, retirado de $A$ Paixão (1965), e escolhido por Luísa Dacosta deixa-nos suspensos, inquietos por não sabermos se a consciência daquela condição de vida lhe porá termo, sem conformação como se dizia a propósito de Irene Lisboa, ou deixará aquela mulher conformada:

(...) batem as sete; tem os olhos cerrados e, cansadamente, reconstitui os gestos gastos a fazer; o dia que se segue élhe memória já; assim o percorreu, envolta em trevas, por semanas santas que duraram séculos e agora sabe apenas que no seu quarto existe alguma pouca claridade; entra pela fresta da janela o frio do sol quase nascendo; não há sombra de dúvida, isto tem de acabar; horas de pôr-se a pé; horas de início, horas de ser; são mais que horas. (Dacosta, 2002: 122)

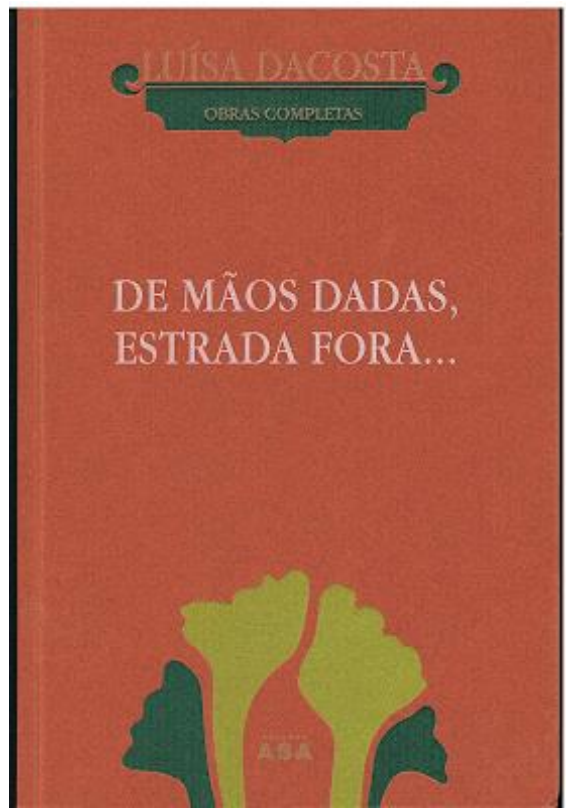

Figura 1: Capa da obra de Luísa Dacosta (acervo pessoal).

A encenação da vida doméstica como lugar de sacrifício e submissão da mulher não tem lugar, na Europa dos finais dos anos 50, inícios dos anos 60, nos livros dedicados a crianças. Seguemse os padrões da mulher do conto tradicional que já só quer saber fazer o seu trabalho e ser 
reconhecida por isso. Mesmo Luísa Dacosta, uma década depois, envolve e dilui a condição feminina nas circunstâncias das desigualdades entre classes sociais. Não será, pois, de estranhar que nessa época se dedicassem aos leitores pequenitos livros como Anita Dona de Casa, de Marcel Marlier (ilustrador) e Gilbert Delahaye (escritor) (1954), o primeiro volume traduzido e publicado em Portugal (1963) que fez os encantos de muitas meninas que têm agora entre 50 e 60 anos. Noutro lugar, já expusemos a nossa opinião sobre o desfasamento deste álbum como objeto a oferecer para iniciação à leitura literária, reconhecendo ainda assim a função que teve à altura do seu lançamento, e apontando o quão errado pode ser utilizarmos a palavra "clássico”, mesmo que seja num subsistema do polissistema literário, como é a $\mathrm{LIJ}^{3}$.

Trata-se, de facto, de uma encenação em livro de um dia em que Anita e o seu irmão Pedro, sozinhos em casa, se dedicam a tarefas domésticas que, habitualmente, veem a mãe fazer. A monotonia do trabalho quotidiano, repetitivo, dá lugar a cenários ideais para que ali nasça uma verdadeira "fada do lar” com os seus “anõezinhos” a ajudá-la. A tarefa alivia-se pelo lado lúdico, onde os animais e os brinquedos ganham vida, como se quer no estereótipo do mundo da cultura infantojuvenil. Os gestos da limpeza trocam o bate-escova-aspira por gargalhadas e disparates inconsequentes. É tudo um faz-de-conta, onde até a bagunça de um quarto de brinquedos se transfigura numa espécie de circo ou espetáculo de vaudeville; os olhos do pré-leitor percorrem a estampa enquanto a voz adulta lhe dita o texto como um guião do que ali se encena, de trás para a frente, ou do fundo de palco para o proscénio:

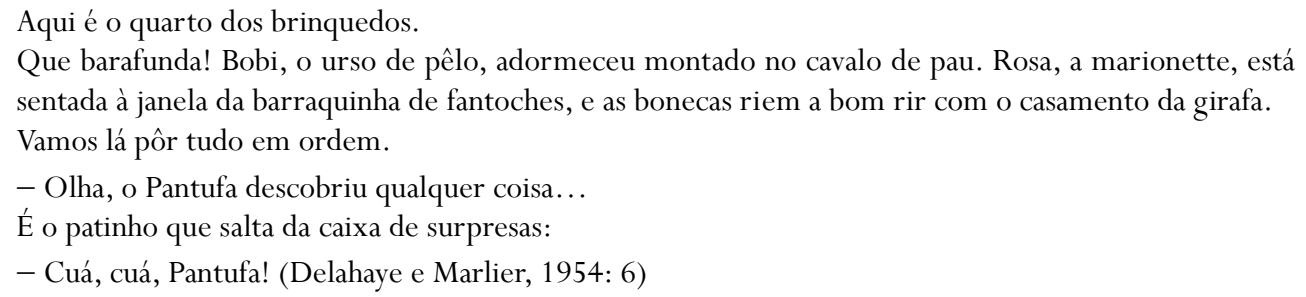

Anita é a imagem da dona de casa, porque Anita faz de conta que é tudo sendo só uma personagem infantil. A ficção que cabe dentro de um livro permite-o, porque a ficção, como a literatura, é o lugar onde se experimenta a vida: os sonhos, as desilusões, as esperanças e as contestações. Ensaia-se ali e talvez se experimente na vida real, se esta não se revelar mais extraordinária do que parecia na ficção. São modelos que duram o tempo que outros modelos, no exemplo das figuras de referência que o leitor encontra fora da ficção, demoram a aparecer, substituindo-os. E é no lugar da ficção que Pedro, o seu irmão mais novo, a ajuda a ser uma dona de

\footnotetext{
${ }^{3}$ Ver Pereira, Cláudia Sousa (2006). “O lugar de Anita na Literatura Infantil: um estudo de caso” (disponível em http://195.23.38.178/casadaleitura/portalbeta/bo/documentos/ot anita cpereira a.pdf).
} 
casa. Na ausência das figuras parentais, Anita transforma-se na autoridade feminina, a quem de resto oferecem aquele dia de trabalho, e Pedro é tao apagado quanto o pai, evocado num par de botas que têm de engraxar. O lar é domínio do feminino, onde ainda que só a brincar, todos parecem capazes de fazer tudo. E tudo é o que parece que, afinal, a mãe faz. Estão criados, com ternura e imaginação contida, os estereótipos que dão ao adulto vontade de louvar, sem verosimilhança nem coerência narrativa, onde o maravilhoso da cena que destacámos, parece servir de testemunha abonatória para a identidade ficcional de tudo o que, tão aparentemente realista, ali se passa.

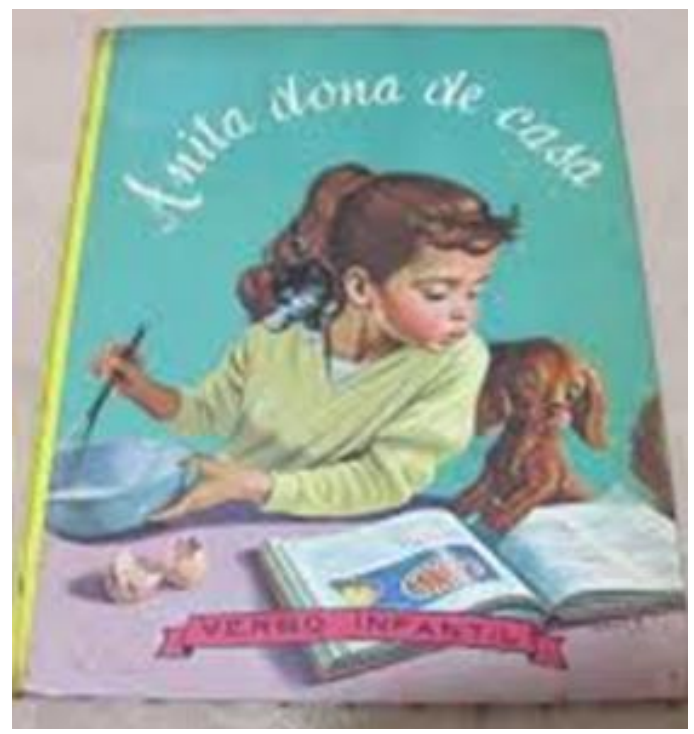

Figura 2: álbum Anita Dona de Casa (acervo pessoal)

Já em Todos Fazemos Tudo um “mix-and-match” ou livro às tiras de Madalena Matoso (2012) este estereótipo é o assunto, virado do avesso. Propõe-se uma alteração desta ordem, sem a barafunda de um quarto de brinquedos, pois a estranheza encaixa nas propostas todas que ali são feitas.

O livro é resultado de uma encomenda do Conselho Municipal para a Igualdade entre Homens e Mulheres da Cidade de Genève, inicialmente com o título Et pourquoi pas toi? (2011). Como é dito na página de guarda:

Este livro nasceu da vontade política do Conselho Municipal e do executivo da cidade de Genebra que desejaram sensibilizar as crianças em idade pré-escolar para a igualdade entre homens e mulheres, qualquer que seja a sua origem. O conceito foi escolhido através de um concurso e realizado pelas Editions Notari, em colaboração com o município da cidade. O livro foi oferecido a todas as crianças que frequentam creches e jardins de infância. A cidade de Genebra, capital dos direitos humanos, congratula-se em contribuir, mesmo que modestamente, com esta pequena obra para a promoção da igualdade entre homens e mulheres. (Matoso, 2012: 2)

São quinze folhas, cortadas a meio, frente e verso preenchidos pelas figuras humanas, ferramentas de trabalho ou objetos do quotidiano que vemos no quotidiano da sociedade contemporânea ainda, muitas vezes, prioritariamente usados apenas ou por homens ou por 
mulheres. O facto da encadernação ser com argolas, opção mais afastada do livro para leitura clássica e mais próxima do caderno de exercícios, facilita a manipulação para executar o “mix-and-match” e talvez predisponha quem manipula a fazer, de facto, um exercício que passe da mão à "massa cinzenta”. E na contracapa surge, naturalmente, a sinopse, a que se confere uma intenção didática expressa:

\footnotetext{
Neste livro não há atividades especiais para meninos e para meninas, para mais velhos e para mais novos, para pais e para mães. Aqui todos fazemos tudo.

Por exemplo: conduzir um trator, estender a roupa, surfar, ir às compras, cozinhar, tratar de um bebé ou tocar guitarra.

Nas nossas vidas também pode ser assim.

Vira as páginas, faz as tuas combinações e observa o que acontece.

Convida os mais crescidos para brincar também!
}

É notável o salto de representações propostas aos pequenos leitores, de Anita até aqui, e que a educação para a qual a geração de Luísa Dacosta tanto contribuiu proporcionou. Sem os temas fraturantes, ainda, este livro não apenas fala de tarefas do quotidiano, como continua a ser um retrato de comportamentos e atitudes, que a evolução da sociedade vai dinamizando, e se transforma numa proposta de normalização, e até incremento, dessas atitudes e desses comportamentos. Não há donos de tarefas distribuídas por género, estas podem ser partilhadas (não acumuladas pela mulher, como parece ser o caso da mãe de Anita que, ao substituí-la tem de pedir ajuda ao irmão Pedro), sendo não apenas socialmente aceite, como assumida e politicamente fomentado.

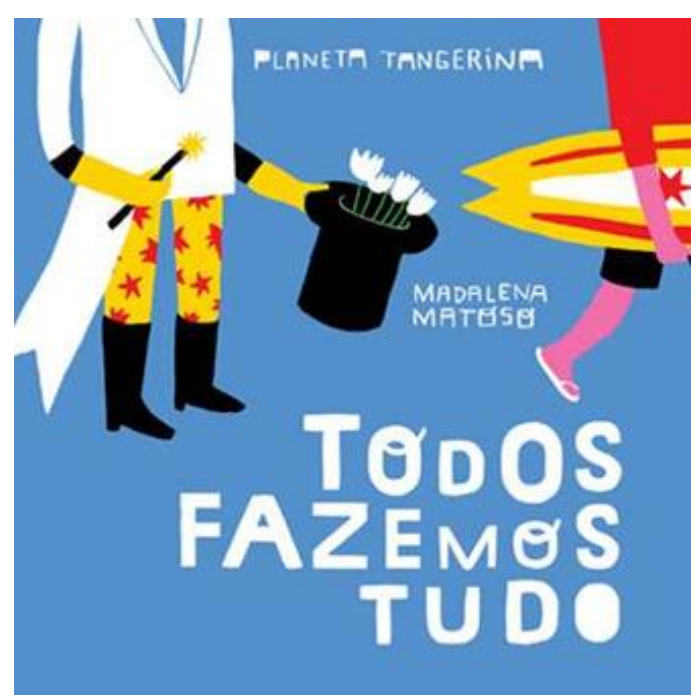

Figura 3: Mix-and-match de Madalena Matoso (acervo pessoal).

Com Os Vestidos do Tiago de Joana Estrela (2013) chegamos a um livro que aborda um tema fraturante, o da identidade de género. É um objeto curioso, quase mais folheto do que livro, disponível para encomenda na página pessoal da autora, já que se trata de um projeto vencedor que concorreu a um desafio da ONG ILGA. Essa simplicidade de folheto, ou talvez catálogo, aumenta a 
surpresa com que a leitura da última frase fecha aquele objeto que folheamos quase incrédulos.

O texto segue direito ao assunto que o título, só por si, tudo diz de provocatório sobre as convenções sociais relativamente ao vestuário como identificador de género e não apenas de sexo. O leitor é, no entanto, desarmado aos poucos se a sua postura for a mais conservadora, já que tudo no livro resiste a essa posição: desde as atitudes dos adultos, à mensagem final que elimina a intenção de quem parece resistir ao exercício da empatia e querer ligar a estranheza à solidão.

Uma simplicidade - na não dramatização, mas também na materialidade inesperada do livro enquanto objeto, como acima dito, que se transmuta num objeto imaterial de um reconhecível peso emocional - que chega a ser comovente. O Tiago vive feliz com os seus gostos, realiza-os e é acompanhado por quem dele gosta, como numa alargada e desejada família feliz.

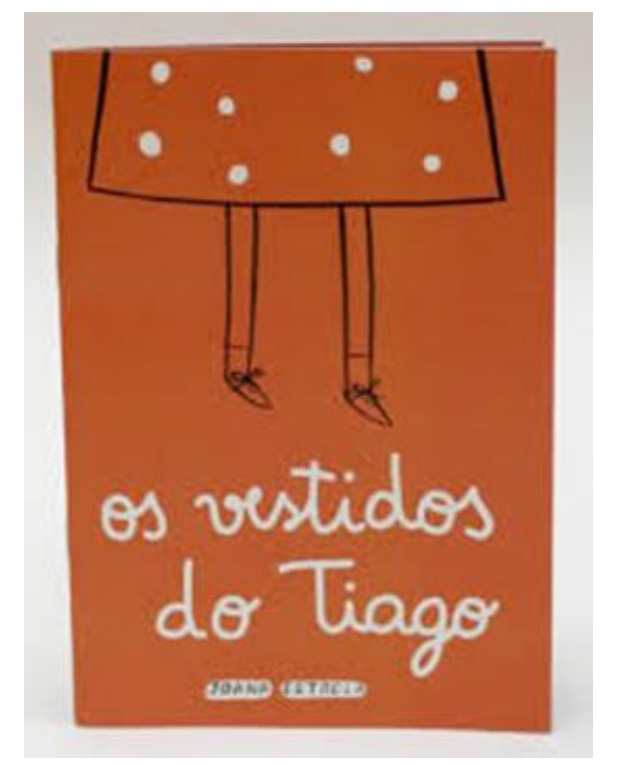

Figura 4: Folheto-livro de Joana Estrela (acervo pessoal).

Finalmente, o nosso último "cantinho" é o surpreendente e talvez chocante Sam Kills Christmas (2018). Nele parece que assistimos ao ambiente diametralmente oposto ao que nos é proposto no modelo generalizado da LIJ, e no caso dos outros “cantinhos” n’ OsVestidos do Tiago. Não porque se tenha voltado aos estereótipos de género, mas porque o ambiente é o da violência e da revolta, em período natalício. E sem fim à vista, como acaba por acontecer com outros "zangados com o Natal”, e cuja personagem mais popular talvez seja o verde monstro Grinch.

O autor, Thomas Ridgewell, é um youtuber inglês de sucesso, conhecido nesse meio por Tomska. A sua intervenção em público é sempre lúdica, muitas vezes apalhaçada como a de tantos outros neste novo "palco", e fazendo aquilo que o seu público espera dele: para além do riso, causas humanitárias, opiniões que apelam à inclusão, tolerância, tudo com recurso ao "disparate" pueril e saudável. Aliás, a forma como, no fim do livro, mistura os agradecimentos e a apresentação da equipa que criou o livro (e sim, um livro é sempre um trabalho de equipa que normalmente fica na sombra), 
revela o tom provocatório, inteligente e sensível ao mesmo tempo: Sobre ele, um "festivity fighter" (um anti-festas) diz-se: "He'd like to thank all the friends and loved ones who tried to show him the true meaning of Christmas; may they rest in peace." ${ }^{4}$. Sobre o co-autor, Eddie Bowley "(who actually really likes Christmas)" e que é, por isso, tratado como um alien, "would like to dedicate this to his totally real wife Alison and definitely human son Rik" ${ }^{\circ}$. Já a ilustradora Dorina Herdewun, "She’d like to thank her parents and that one teacher who called her an idiot"”.

As referências que o texto faz ao mundo que jovens, e cada vez mais crianças, vivem na Internet - desde o consumo de opinião, ficção, intervenção pública ou só comércio mesmo - e que os torna parte daquele mundo ficcional que no livro, por definição mais estático, os eleva ao grau de connoisseurs, criam um ambiente em que os leitores estão à vontade, mesmo longe do "black mirror". O texto recorre às onomatopeias como substantivos ou verbos, mantendo até o grafismo que o código da BD nos ensinou.

Dá-se também, através da paronomásia, outra ortografia a palavras que, mantendo o significado são homófonas, com referências diretas ao Natal e ao mundo bélico, mantêm o ambiente anti-Natal anunciado logo no título:

Mas o que mais importa referir a propósito deste livro, é o facto de o género de Sam ser mantido sempre desconhecido. E quando dizemos sempre, falamos também da ilustração criada para

representar Sam. O texto verbal recorre ao pronome da terceira pessoa do plural "they", o texto icónico mostra-nos uma criança sem sinais distintivos do "papel de género". E tudo funciona na perfeição (mesmo dentro do quadro de violência), já que o tom do texto é mesmo o de uma balada ou rimance, que uma leitura em voz alta pode mesmo acentuar.

Sem didatismos, nem moralidades apaziguadoras, este livro de Tomska não deixa de ser um produto cultural que responde ao gosto do seu potencial leitor, o que poderia ser desastroso em termos da qualidade da obra, como proporciona uma profunda e riquíssima oportunidade para aprender a ler literariamente, como adiante, nas conclusões, veremos.

\footnotetext{
4 "Gostaria de agradecer a todos os amigos e entes queridos que tentaram demonstrar-lhe o verdadeiro sentido do Natal; que descansem em paz” (tradução nossa).

5 "(que gosta mesmo do Natal)" (tradução nossa).

6 "gostaria de dedicar isto à sua completamente real mulher Alison e ao seu definitivamente humano filho Rik" (tradução nossa).

7 "Gostaria de agradecer aos seus pais e aquela professora que lhe chamou idiota" (tradução nossa).
} 


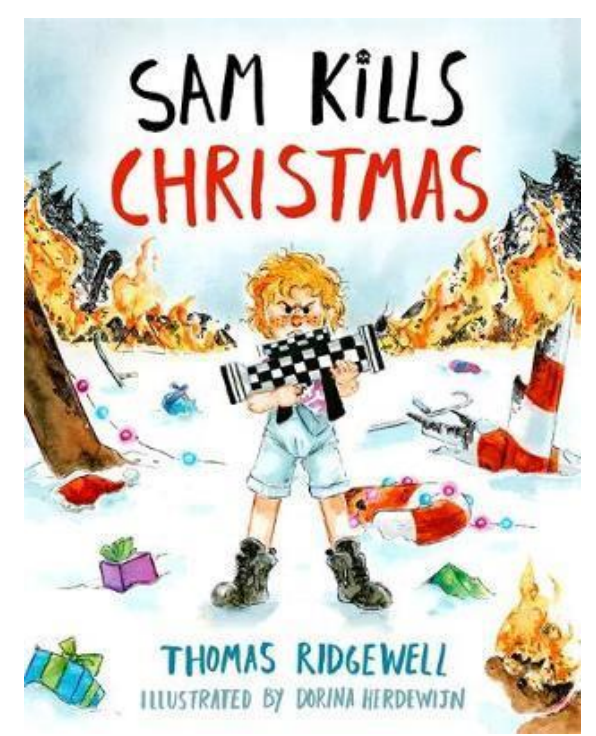

Figura 5: Sam Kills Christmas do autor e youtuber inglês Thomas Ridgwel AKA TomSka (acervo pessoal).

\section{Canetti e McLuhan}

Para já, interessa-nos também o lugar dos cinco livrinhos numa cultura que oscila entre a democratização do acesso aos mesmos e a massificação do seu público ou recetor potencial. É um facto que os objetos culturais dedicados a crianças e jovens se constituem, na nossa contemporaneidade, maioritariamente como ótimos produtos comerciais. Mesmo o sistema político democrático, que tem como princípio assegurar a igualdade de oportunidades e o combate a assimetrias, e tem como missão evitar o negócio na transação de bens culturais e educativos, não seria sustentável se não pensasse a uma escala que tome a excecionalidade de alguns como isso mesmo, e tenda a produzir políticas, e instrumentos de implementação dessas políticas, que se adaptem à generalização. Isto tem como consequência uma padronização a roçar a massificação, e apenas mitigada precisamente pela intervenção o mais atenta possível dos mediadores que levam ao seu funcionamento junto dos públicos a que se dirigem.

Importava-nos, pois, perceber o que no advento dessa massificação foram as projeções que teria implicações no fenómeno da comunicação e do relacionamento dos indivíduos entre si e com os produtos criados nesse contexto do princípio da mass culture. Foi assim que chegámos, ou melhor regressámos mais uma vez, a Canetti e a McLuhan. Vejamos o que, do que pensaram e escreveram, nos pode ser útil agora.

O comportamento de seres humanos convocados para se reunirem e agirem como coletivo parece reagir, segundo Canetti, de forma inconsciente perante determinadas condicionantes. Uma forma atávica de reagir a estímulos que convocam a participação dos cidadãos na vida coletiva, 
portanto. Isto sucede, de acordo com o teórico alemão, de duas formas: quando o espaço é público e aberto, parece haver menos condicionamento exterior, e o coletivo acaba por se desintegrar, por dispersar; quando o ambiente parece controlado, e sublinhe-se o "parece", o coletivo tende a manter-se assim, junto. O comportamento de massas, por definição, desconsidera o individual e particular e tende a tratar todos os que compõem um coletivo por igual. Há uma padronização de características e, por isso, as ferramentas tecnológicas que estabelecem relações entre si e com o ambiente, os media, apresentam códigos decifráveis por todos, criando assim ao mesmo tempo a ilusão da igualdade e o fim das relações, por exemplo, melhor-pior.

Esta decifração dos códigos como instrumentos unificadores, verificada a identificação de uns -códigos- com os outros -recetores-, é facilmente manipulável por quem conhece o funcionamento dos códigos para além da mera utilização. Exclusividade de quem sabe como é que se faz para criar o meio que dê unidade ao contexto onde muitos, num ambiente fechado e por isso ainda com mais afinidades partilhadas -nem que seja os mesmos tempo e espaço- se encontram para agir. Já agir reagindo ao estímulo, que o meio certo para o contexto em que se encontram as (re)ações, parece um desenrolar-se por inércia. E essa inércia leva a comportamentos inconscientes, o tal atavismo, uma espécie de herança que não se questiona.

Já em contextos de conflito, e pensamos sobretudo nos contemporâneos de confronto de opiniões em questões fraturantes, assistimos, no passado como agora, a comportamentos tribais, de coletivos em confronto. McLuhan explicou estes comportamentos através da adaptação do corpo humano, e dos seus sentidos, e que condicionam também a diferença entre atitudes públicas e privadas. Segundo McLuhan, antes da invenção da escrita com recurso ao alfabeto (e não representações pictóricas), o homem vivia num mundo onde todos os sentidos eram equilibrados e simultâneos, um mundo de ressonância tribal, uma cultura oral estruturada por um sentido auditivo dominante da vida. O principal meio de comunicação com coletivo era a fala, a palavra dita em presença e, portanto, nenhum homem teria mais ou menos informação do que outro. E isto significava que havia pouco individualismo e especialização, as marcas do homem ocidental "civilizado". As culturas tribais não compreendem o conceito do indivíduo ou do cidadão separado e independente, quando se trata de assunto público. As culturas orais agem e reagem simultaneamente, ao passo que agir sem reagir é privilégio do homem letrado, "destacado".

Esta perspetiva dos comportamentos humanos em função das tensões tribal/individual, ouvir/ver, público/privado, oral/escrito realçam a importância dos mediadores, no contexto contemporâneo, da informação e da formação de opinião, na resolução dos conflitos decorrentes dessas tensões e onde elas próprias são "a" matéria ou "o" assunto. Mesmo quando os mediadores são 
os próprios criadores dos objetos culturais, quando imaginamos a criança, ou o jovem, deixados a sós com eles. É assim que os objetos podem passar a ser geradores de opinião, sem usar o método propagandístico, em que a opinião é apresentada como informação e não como uma posição sobre uma informação. E mesmo quando esses objetos não colocam em questão determinados assuntos que se podem transformar, por exemplo, em perpetuação de preconceitos.

O campo das questões de género é fértil em objetos destes. Objetos que, por morarem na idade áurea da infância e sobre os quais muito tempo, nostalgicamente, passou, criam dificuldades em permitir um olhar mais crítico. Do outro lado, teremos sempre acusações de manipulação de mentalidades, como se as ideologias tivessem de criar-se em ambientes assépticos, como não há na vida em sociedade, seja ela tribal ou supostamente global.

\section{As questões em torno do género: propostas e conclusões}

Relembremos, então, as questões que propomos deixar para reflexão a partir dos livros que escolhemos: A consciência da diferença parte da pressão social ou da orientação individual? O convívio intergeracional pode promover a continuidade ou, pelo contrário, incentivar a contestação aos preconceitos de género? E essas, a continuidade ou a contestação, dependem fundamentalmente da cíclica generation gap ou antes de mudanças societais?

Não esqueçamos, também, que do que nos propusemos tratar aqui foi de leitura literária, aquela que toma o livro como objeto em que se pode discutir intencionalidades estética, ética ou política, não descarta a intencionalidade lúdica, a vários níveis como veremos. Não de livros que falam sobre questões de género (ou outro tema qualquer), de forma óbvia, panfletária, só com técnica e agenda mas sem arte, como acontece na esmagadora maioria dos livros que são editados para crianças e jovens.

Nos excertos comentados de Luísa Dacosta, definitivamente literários e sem necessidade de se afirmar neste campo de estudos, a condição feminina surge mesclada com as questões da condição humana em sociedades desiguais. Era essa a questão de género a resolver no contexto histórico quer da recolectora de textos, quer dos autores canónicos dos textos ali recolhidos. É a palavra "liberdade", acompanhada da palavra "democracia" que se quer desvendar e se revela nas entrelinhas dos excertos e nos comentários que lhes são feitos. A liberdade que nasce do livre pensamento, só transformado em ação, e plenamente vivida, em democracia que não há. O sonho dessa liberdade é o motor que talvez impulsione o passo, revolucionário, da mudança. Primeiro de mentalidades, depois de regime político. E é por isso que o ex-libris de Luísa Dacosta é, 
precisamente, No sonho, a liberdade.

Ao mediador adulto, perceber isto mesmo e descobrir ao longo da antologia esta mensagem subliminarmente tratada, é uma das possibilidades da leitura literária da obra que, como literária, proporciona outras leituras e outros deleites. Percebe-se que a mudança também terá de se fazer com inconformismos, que as personagens literárias questionam pressões sociais, ou que os enredos magistralmente entretecidos pela linguagem literária - que se analisa e interpreta - proporcionam ficcionalmente soluções para resistir a determinadas perpetuações, ainda que só com o tempo surja a oportunidade de mudar. É, em termos do chamado “papel da arte”, esta partilha da questão de género com a denúncia da situação da sociedade que pode contribuir para a mudança societal.

Já a leitura daquele álbum, das centenas que, entretanto, foram editados, da sempre jovem Anita pouco questiona o lugar do género no funcionamento da sociedade, sobretudo na intimidade doméstica. A casa, e as tarefas que ali se têm de desempenhar, são monopólio feminino sem contestações, nem rebeldias. A casa é o lar de fadas, felizes e benfazejas. A harmonia de um lar esconde a solução para todo e qualquer conflito que "lá fora" possa existir, na mais pueril das mensagens que se possa transmitir. É o lugar rural, da aldeia em que todos se conhecem e convivem, protegidos da ameaça estranha. É por isso que, contrariamente a tudo o que dizemos às nossas crianças que vivem expostas ao perigoso mundo das tecnologias e dos "lobos-maus" que as povoam a cada clic, a Anita e o Pedro mexem no fogão a gás e abrem a porta ao leiteiro que lhes entra casa adentro. Num mundo assim, em que todos são iguais porque, e só porque, igualmente felizes, não há questões a colocar. Só modelos a seguir, ordeiramente, perpetuando tradições, sem pressões nem dúvidas. E, claro, também sem interesse nenhum.

O livro às tiras de Madalena Matoso é uma revolução. É o livro mais autonomamente manipulável e lido pelos mais pequenitos. É um livro de fazer, sobre fazer, qualquer que seja a idade e o género, em ambos os "fazer". Não havendo a negação de nenhuma prática ou costume, e como tal sem julgamentos a pressões sociais, apresenta-se pela positiva. A estranheza de certas combinações das tiras pode provocar sobretudo o riso, mas a coincidência confirma a correção dessa forma de "fazer". Mesclam-se atividades públicas e privadas, joga-se com a "limpeza" de traços e objetos nas páginas, pares ou ímpares, e onde tudo parece caminhar no sentido do futuro, para a frente e para onde, ocidental e normalmente, se abrem e leem os livros e a civilização progressista ${ }^{8}$. E talvez esta seja a principal condicionante histórica e tradicional nesta "revolução", o espaço de reconhecimento e identificação que serve a comunicação entre o mediador adulto e o pré-leitor,

\footnotetext{
${ }^{8}$ Noutra cultura, com outra direção de escrita, também as imagens deveriam ser transpostas no sentido para que se abre o livro, uma questão que os estudos em LIJ também discutem no âmbito da edição e tradução.
} 
mesmo subentendida e apenas revelada numa leitura mais atenta e, diríamos nós, literária.

Com Sam Kills Christmas talvez seja o mediador adulto quem claudique na apreciação do livro: a estética dos textos -verbal e icónico- causará, parece-nos, uma abordagem dificilmente partilhável entre gerações de, por exemplo, avós e netos, um par ainda tradicionalmente usado, em algumas sociedades, na promoção da leitura e do primeiro contacto com o mundo das histórias e dos livros. É um livro que requer alguma maturidade aos jovens leitores, sobretudo para apreciarem o jogo sons-sentidos das palavras no contexto e para o qual o mediador adulto poderá chamar a atenção. Um ludismo especial, negro e triste, mas que falando a mesma linguagem da violência não deixa de encerrar uma mensagem que apela à empatia, valor tão bem cotado na sociedade atual. A contestação às injustiças expressa-se pelo uso das mesmas armas -linguagem e referenciais bélicos e violentos- do que é maléfico mas em contexto ficcional, o único em que é tolerável.

O livro de Natal de Tomska é, sem dúvida, feito para chocar primeiro e, no fim, dar colo. É esse o seu design literário. É um objeto cultural que se aproximará mais facilmente de crianças e jovens habituados a outros ambientes que não o do livro e da leitura: o gaming e a net. Ainda assim, e para não cometermos o mesmo erro dos adultos que, com o aparecimento da indústria Disney e o facilitado acesso à televisão, deixaram os mais novos sozinhos a "brincar e a crescer" com eles, também o mediador adulto pode e deve ler este objeto e transformá-lo num momento de leitura literária. Cabe-lhe acompanhar os "truques" do texto que corre em ritmo de balada, olhar e ver com atenção o que o texto icónico escolhe representar. Veja-se sobretudo os três últimos pares de texto verbal e icónico. E quanto às questões de género, a forma como os autores (de texto e da ilustração) resolvem eventualmente colocá-las, revela-se, para o mediador adulto que a queira proporcionar, uma abordagem ao livro para esse sentido de leitura - sempre na perspetiva de ser mais uma leitura possível, que é o que faz a leitura literária.

A função do mediador adulto destes objetos com os seus destinatários implícitos pode sempre melhorar, se ponderarmos estas questões ao pegarmos num destes livros e o lermos, ao vivo, com crianças ou jovens que são de uma geração profundamente marcada pelos comportamentos que Canetti e McLuhan descrevem a propósito dos "consumidores" de objetos culturais, e por isso escolhemos obras que distam entre si duas gerações. Autores e leitores manterão sempre o gap geracional, quando se trata de LIJ, pelo que cumpre em primeiro lugar ao texto (ou textos, pensando no icónico e material) e depois ao mediador aproximá-los na leitura literária, no usufruto do objeto e, depois, na potencialização de criar argumentários que alimentem ou convivam com o gap de textos datados de gerações distantes. É dessas quebras do horizonte de expetativas que nasce a possibilidade de se manter a sempre-eterna pergunta -o que é literatura?- e a que as 
questões em torno do género poderão sempre proporcionar mais e novas respostas.

\section{Referencias bibliográficas}

\section{Estudos e obras teóricas}

CANETTI, E. (1960[1978]). Crowds and Power. New York: Seabury Press.

EVEN-ZOHAR, I. (1979). "Polysystem Theory”. Poetics Today, 1 (1-2), 287-310.

FLUSSER, V. (2010), O mundo codificado: Por uma filosofia do design e da comunicação. São Paulo: Cosac \& Naif ( $2^{\mathrm{a}}$ edição).

HEILBORN, M.L. (1994). “De que gênero estamos falando?". Sexualidade, Gênero e Sociedade. Ano 1, 2 CEPESC/IMS/UERJ. Consultado o 16 de novembro de 2017, http://www.clam.org.br/bibliotecadigital/uploads/publicacoes/de\%20que\%20genero \%20estamos\%20falando.pdf

HOLLINDALE, P. (2011). The Hidden Teacher - Ideology \& Children's Reading. The Thimble Press: UK.

MC LUHAN, M. (1962[2011]). The Gutemberg Galaxy. University of Toronto Press.

RAMOS, A. M. (2010). "Saindo do armário - Literatura para a infância e a reescrita da homossexualidade". Forma Breve, 7, 293-312. https://doi.org/10.34624/fb.v0i7.6649

SCOTT, J. (1989). Gender and the politics of history. New York: Columbia University Press.

\section{Obras trabalhadas}

DACOSTA, L. (1970-73[2002]). De Mãos Dadas, Estrada Fora...(vols. I e II). Porto: Asa Editores.

DELAHAYE, G. e MARLIER, M. (1954[1963]). Anita Dona de Casa. Lisboa: Editorial Verbo.

ESTRELA, J. (2014). Os Vestidos do Tiago. [Disponível por solicitação por correio à autora ou em versão electrónica em http://joanaestrela.tumblr.com/post/44287689700/sentyesterday-my-submission-for-ilga-portugals].

MATOSO, M. (2012). Todos Fazemos Tudo. Lisboa: Planeta Tangerina.

RIDGEWLL, T. (2018). Sam Kills Christmas. London: sphere. 